\title{
AS PRÁTICAS DE REDUZIR, REUTILIZAR E RECICLAR NO INSTITUTO POLITÉCNICO DA GUARDA
}

\author{
PRACTICES TO REDUCE, REUSE AND RECYCLE IN THE POLYTECHNIC \\ INSTITUTE OF GUARDA \\ PRÁCTICAS PARA REDUCIR, REUTILIZAR Y RECICLAR EN EL \\ INSTITUTO POLITÉCNICO DA GUARDA
}

\author{
Cecília Rosa (cecirosa@ipg.pt) * \\ Cecília Fonseca (cfonseca@ipg.pt) ** \\ José Alexandre Martins (jasvm@ipg.pt) *** \\ José Miguel Salgado (miguelsal@ipg.pt) **** \\ Maria Manuela Figueira (mfigueira@ipg.pt) **
}

\section{RESUMO}

Dada a atual quantidade de resíduos ambientalmente nocivos, é fundamental a consciencialização individual e das organizações face à política dos "3R's", a redução, a reutilização e a reciclagem. Neste trabalho pretende-se aferir os conhecimentos e comportamentos em relação à prática dos "3R's" na comunidade do Instituto Politécnico da Guarda (IPG), em Portugal, e identificar situações que carecem de medidas pró-ambientais. Para tal, realizou-se um estudo transversal, quantitativo e descritivo baseado num instrumento de recolha de dados, distribuído via correio eletrónico, que obteve a participação de 342 indivíduos.

Mais de $50 \%$ dos participantes manifestaram ter conhecimentos sobre o tema "3R's". Concluiu-se que 99,1\% dos indivíduos optaram "Algumas vezes" a "Sempre" pela atitude adequada face aos "3R's". Para a maioria não existe uma boa sinalização dos pontos de reciclagem no IPG (51,2\%), nem uma política proactiva face aos resíduos $(54,1 \%)$.

Pode concluir-se que os conhecimentos e comportamentos dos respondentes são francamente positivos, mas identificaram-se pontos que exigem medidas de intervenção.

Palavras Chave: reduzir, reutilizar, reciclar, comportamento ambiental, comunidade do IPG.

\section{ABSTRACT}

Given the current amount of environmentally harmful waste, it is essential to raise individual and organizational awareness of "3R's" policy, reduction, reuse and recycling. This work aims to assess the knowledge and behaviours regarding the practice of "3R's" in the community of the Polytechnic Institute of Guarda (IPG), in Portugal, and identify situations that need pro-environmental actions. A cross-sectional, quantitative and descriptive study was performed. A data collection tool, distributed via email, was developed, and was answered by 342 individuals.

More than $50 \%$ of participants said they had knowledge of the "3R's" theme. It was concluded that $99.1 \%$ of individuals chose "Sometimes" to "Always" for the proper attitude towards "3R's". For the 
majority there is no good signalling of recycling points in the IPG (51.2\%), nor a proactive waste policy $(54.1 \%)$.

It can be concluded that knowledge and behaviours were positive, but points were identified that require intervention.

Keywords: reduce, reuse, recycle, environmental behaviour, IPG community.

\section{RESUMEN}

Dada la cantidad actual de residuos, ambientalmente perjudiciales, es esencial aumentar la conciencia individual y organizacional de la política de las "3R": reducción, reutilización y reciclaje. Este estudio tiene como objetivoe valuar el conocimiento y los comportamientos relativos a la de la práctica de "3R" en el Instituto Politécnico de Guarda (IPG), en Portugal, e identificar situaciones que necesitan medidas pro ambiéntales. Para ello, se realizó un estudio transversal, cuantitativo, y basado en un instrumento de recogida de datos distribuido por correo electrónico, que obtuvo la participación de 342 personas.

Más del $50 \%$ de los participantes tenía conocimiento del tema/ sobre el tema (de las) "3R". Se concluyó que el $99.1 \%$ de los individuos había elegido entre "A veces" y "Siempre" la actitud adecuada hacia "3R". Para la mayoría no hay una buena señalización de los puntos de reciclaje en el IPG $(51,2 \%)$, ni una política proactiva en materia de residuos $(54,1 \%)$.

Se concluye que el conocimiento y los comportamientos de los encuestados son en gran medida positivos, pero se identificaron puntos que requieren medidas de intervención.

Palavras-clave: reducir, reutilizar, reciclar, comportamiento ambiental, comunidad IPG.

Submitted: $10^{\text {th }}$ November 2020

Accepted:20 ${ }^{\text {th }}$ March 2021 


\section{INTRODUÇÃO}

A alteração do estilo de vida das pessoas, nomeadamente no que concerne aos seus hábitos de consumo, tem levado ao aumento da quantidade de produtos disponíveis no mercado e à diversificação da forma como estes são colocados à disposição do consumidor. Esta diversificação tem conduzido a um aumento significativo da produção de resíduos, criando tensões a montante e a jusante da cadeia de valor das matérias-primas.

Num cenário em que o aumento do consumo se reflete proporcionalmente na quantidade de resíduos que é necessário eliminar, temos vindo a assistir a um intenso debate envolvendo várias questões ambientais associadas à sustentabilidade do planeta. Acresce a estas questões o impacto ambiental causado pela pressão sobre a cada vez maior necessidade de matérias-primas, com elevados consumos de água e energia implicados não só na fase de extração, mas também no transporte e posterior transformação e fabrico dos produtos. Esta tendência conduziu, por sua vez, a um segundo problema: a falta de espaço para instalar aterros adequados onde eliminar os resíduos produzidos, bem como a necessidade de resolver os impactos dos mesmos, nomeadamente a produção de águas lixiviadas e de metano, um gás associado às alterações climáticas.

Nasce, assim, a necessidade de alterar a forma como os resíduos são vistos, começando pela necessidade de reduzir a sua produção. Associado a movimentos ambientalistas e a cidadãos ambientalmente preocupados, surge um novo conceito, a política dos "3 R's": Reduzir, Reutilizar e Reciclar que consiste num conjunto de medidas de ação adotadas na Conferência da Terra realizada no Rio de Janeiro em 1992, bem como no 5o Programa Europeu para o Ambiente e Desenvolvimento de 1993.

O primeiro "R", reduzir, consiste em diminuir o consumo e utilizar somente o necessário, o segundo "R", reutilizar, consiste na procura de novas utilidades para o que se deitaria fora depois de utilizar e, por fim, o terceiro "R", reciclar, que envolve a separação do lixo para as transformações químicas ou físicas necessárias à produção de novos produtos (ChierritoArruda et al., 2018).

Em Portugal, e segundo a Entidade Reguladora dos Serviços de Águas e Resíduos (ERSAR, 2018), são produzidos anualmente cerca de 4,5 milhões de toneladas de resíduos urbanos. A legislação portuguesa sobre os resíduos está de acordo com o Dec. Lei no 73/2011 de 17 de junho que altera o regime geral da gestão de resíduos e transpõe a Diretiva n.o 2008/98/CE, do Parlamento Europeu e do Conselho, de 19 de novembro, relativa aos resíduos. Neste decreto "Prevê-se a aprovação de programas de prevenção e estabelecem-se metas de reutilização, reciclagem e outras formas de valorização material de resíduos, a cumprir até 2020".

Neste contexto, foi elaborado o Plano Estratégico para os Resíduos Urbanos, para Portugal Continental de acordo com a Portaria 187/2014 de 17 de setembro. No PERSU 2020 (2014, p.7) é referido que "O PERSU 2020 é o novo instrumento de referência da política de resíduos urbanos em Portugal Continental. O PERSU 2020 estabelece a visão, os objetivos, as metas globais e as metas específicas por Sistema de Gestão de Resíduos Urbanos e as medidas a implementar no quadro de resíduos urbanos no período 2014 a 2020, bem como a estratégia que suporta a sua execução".

São várias as organizações portuguesas preocupadas com as políticas ambientais nomeadamente na gestão dos resíduos. Por exemplo, a Agência Portuguesa do Ambiente tem por missão: 
Propor, desenvolver e acompanhar a gestão integrada e participada das políticas de ambiente e de desenvolvimento sustentável, de forma articulada com outras políticas sectoriais e em colaboração com entidades públicas e privadas que concorram para o mesmo fim, tendo em vista um elevado nivel de proteção e de valorização do ambiente e a prestação de serviços de elevada qualidade aos cidadãos (Agência Portuguesa do Ambiente, 2018).

Com a constituição dos sistemas de gestão de resíduos urbanos, Portugal passou de uma situação em que existiam 257 entidades gestoras de resíduos para o estado atual, onde em todo o território continental existem apenas 23 entidades de gestão de resíduos urbanos: Doze multimunicipais - Valorminho, Resulima, Braval, Resinorte, Suldouro, Valorlis, ERSUC, Resiestrela, Valnor, Valorsul, Amarsul e Algar; Onze intermunicipais - Lipor, Valsousa, Resíduos Nordeste, Ecobeirão, Ecolezíria, Resitejo, Amtres (Tratolixo), Amde (Gesamb), Amagra (Ambilital), Amcal e Resialentejo (Naturlink, 2018; Agência Portuguesa do Ambiente, 2018).

O problema da gestão dos resíduos sólidos urbanos na sociedade atual, exige a participação da sociedade na integração das responsabilidades individuais com as ações políticas (Chierrito-Arruda et al., 2018).

A consciencialização individual sobre os problemas ambientais e a forma como se faz a gestão dos resíduos são fundamentais, uma vez que o envolvimento dos cidadãos neste problema é a única forma de estimular a sua participação na adoção de comportamentos que contribuam para a sustentabilidade no processo de gestão dos resíduos (Tadess, Ruijs, \& Hagos, 2008). A promoção de práticas de reutilização e reciclagem do lixo doméstico pode ter uma influência considerável na redução da produção de resíduos (Pandey, Surjan, \& Kapshe, 2018).

A gestão dos resíduos passa pela aplicação da política comportamental dos "3R's": reduzir, reutilizar e reciclar a quantidade de lixo produzido e, neste sentido, a participação e o comportamento do cidadão comum é fundamental existindo alguns cuidados importantes a ter, tais como, por exemplo: na compra de novos artigos é de extrema importância adquirir, sempre que possível, produtos que sejam reutilizáveis, como guardanapos de pano, sacos de pano para as compras diárias, embalagens reutilizáveis para armazenar alimentos, etc.; comprar apenas o necessário, evitando desperdícios; imprimir ou fotocopiar apenas o necessário e nas quantidades necessárias; sempre que possível, optar por produtos sem embalagem (por exemplo, frutas e legumes); preferir as embalagens grandes às pequenas ou recusar publicidade não endereçada.

De facto, quanto maior for o número de vezes que uma embalagem é reutilizada, mais tempo levará a entrar no circuito do lixo. Desta forma, otimiza-se a sua utilização e tira-se um maior proveito da matéria-prima, energia e água gastas na sua produção.

Não havendo possibilidade de evitar a produção do resíduo nem de reutilizar o produto, devese separar o material para reciclagem. Desta forma, procura-se reaproveitar a energia e as matérias-primas, gastas nesse produto, na sua transformação num novo produto, cujo fabrico terá um menor impacte ambiental comparando com a produção de um produto de raiz.

Já foram realizados inúmeros estudos de investigação que abordam as relações dos indivíduos com o meio ambiente em que vivem fazendo-os refletir sobre o bem-estar e a qualidade de vida, os conhecimentos, os pensamentos e comportamentos em relação à formação e reutilização dos resíduos produzidos (Querino, Pereira, \& Barros, 2018). Também já foi estudado o nível de conhecimento ambiental, preocupações, atitudes e comportamentos em alguns países (Chan, 1999; Wehrmeyer, \& Mcneil, 2000; Pandey, Surjan, \& Kapshe, 2018). 
Em particular, no que diz respeito a comunidades de estudantes, já foram realizados trabalhos de investigação na tentativa de caracterizar os seus conhecimentos e comportamentos para com o meio ambiente.

Alibeli e Johnson (2009) indicam níveis moderadamente elevados de preocupação com o meio ambiente entre estudantes universitários do Bahrein, Jordânia, Qatar e Arábia Saudita. Neste estudo, os autores também observaram que: a preocupação com o meio ambiente varia de acordo com as características socioeconómicas e demográficas dos estudantes; as mulheres estão mais preocupadas com o meio ambiente do que os homens; as pessoas pertencentes à classe média mostram mais preocupação com o meio ambiente do que as de classe mais baixa.

Erhabor e Dona (2016) estudaram a avaliação dos conhecimentos e atitudes dos alunos em relação ao meio ambiente numa universidade federal no estado de Edo, na Nigéria. Neste caso, os estudantes revelaram um elevado nível de conhecimento e uma atitude positiva em relação ao meio ambiente.

Târtiu (2011) estudou o nível de conhecimento e consciencialização sobre os resíduos municipais entre estudantes da Academia de Estudos Económicos de Bucareste, as suas atitudes no desenvolvimento de atividades relacionadas com os resíduos e ainda as diferenças que existiam em relação à consciencialização, o conhecimento e preocupação dos estudantes de acordo com género, idade, faculdade ou situação de emprego. Das conclusões apresentadas destaca-se o facto de a maioria dos estudantes estar consciente dos problemas do desperdício e da importância da reciclagem, bem como, o facto de referiram atitudes próambientais.

Também no trabalho de Embong et al. (2013) é avaliada a compreensão das práticas dos "3R's" entre os estudantes de várias escolas secundárias de cinco estados da Malásia. Uma das conclusões foi que os estudantes tinham uma boa compreensão sobre a prática dos "3R's", mas com maior compreensão sobre a Reciclagem seguida da Reutilização e por fim da Redução. Verificaram ainda que estudantes do meio urbano tinham melhor entendimento sobre a redução e que os estudantes do meio rural compreendiam melhor a Reciclagem. No entanto todos eles estavam conscientes em relação aos benefícios obtidos com a prática dos "3R's".

A importância do impacto dos conhecimentos e comportamentos da população estudantil é cada vez maior, no sentido de uma mudança de atitudes e hábitos em relação à prática dos "3R's" (Demoly \& Santos, 2018). A escola é o local propício para a formação de gerações comprometidas com a conservação dos recursos ambientais, o combate ao desperdício, a reutilização de materiais não-lixo como fonte de matéria-prima para a indústria e a reciclagem do próprio lixo.

O desenvolvimento de ações, organizadas por entidades públicas ou privadas, que promovam a prática dos "3R's" na comunidade em geral e no contexto da escola, em particular, são um meio de contribuir para a literacia ambiental. Neste contexto, a empresa Valorsul, que trata e valoriza os resíduos urbanos de 19 municípios das regiões de Lisboa e Oeste de Portugal, desenvolve, à semelhança de outras, várias atividades e iniciativas de educação e sensibilização ambiental. Uma dessas atividades, realizada anualmente em novembro e de âmbito europeu, é a Semana Europeia da Redução de Resíduos (EWWR).

A EWWR promove a implementação de ações de sensibilização sobre recursos sustentáveis e gestão de resíduos durante uma única semana, encorajando um vasto leque de audiências a envolver-se, como por exemplo autoridades públicas, empresas privadas, a sociedade civil e os próprios cidadãos. 
No âmbito da 8a edição da EWWR organizada pela Valorsul, foi delineado um estudo cujo alvo foi a comunidade escolar do Instituto Politécnico da Guarda (IPG) com o objetivo de aferir os conhecimentos e práticas dos funcionários, docentes e estudantes relativamente ao tema "Reduzir, Reutilizar e Reciclar". Assim, pretendeu-se caracterizar esta realidade e, consequentemente, identificar eventuais situações a carecerem de medidas de intervenção, no sentido de se promoverem comportamentos pró-ambientais nesta comunidade.

Após esta introdução ao tema, onde se apresentou a motivação e o objetivo do estudo, seguese a apresentação da metodologia adotada e a análise e discussão dos resultados, onde será caracterizada a amostra e apresentados os conhecimentos gerais, os comportamentos e as atitudes em relação à prática dos "3R's", bem como as práticas no IPG. Por fim, na conclusão, serão destacados os principais resultados e identificados os pontos que carecem de medidas de intervenção.

\section{METODOLOGIA}

A população alvo do presente estudo foi a comunidade das escolas do Instituto Politécnico da Guarda (IPG) que inclui estudantes, docentes e funcionários. Em termos metodológicos optou-se por um estudo transversal com uma abordagem quantitativa e descritiva.

A recolha de informação baseou-se num instrumento de recolha de dados que foi desenvolvido para o efeito, construído com a ferramenta Google Formulários. O instrumento de recolha de dados (ANEXO I) utilizado foi composto por quatro partes, com um total de dezasseis questões fechadas e uma aberta, acompanhado de um breve resumo dos objetivos do estudo e do consentimento livre, informado e esclarecido.

A primeira parte do instrumento destinou-se à caracterização da amostra, nomeadamente o vínculo (estudante, aluno, docente) com o IPG, a escola a que estão afetos (Escola Superior de Tecnologia e Gestão-ESTG, Escola Superior de Educação, Comunicação do Desporto ESECD, Escola Superior de Saúde-ESS, Escola Superior de Turismo e Hotelaria-ESTH), o sexo, a idade e, no caso dos alunos, o tipo de curso que frequentavam (Técnico Superior Profissional-TeSP, Licenciatura ou Mestrado). Na segunda parte, abordou-se os conhecimentos gerais sobre o tema reduzir, reutilizar e reciclar, tendo-se solicitado aos inquiridos que manifestassem o grau de concordância ("Concordo", "Discordo", "Não sei") com um conjunto de afirmações sobre o tema. A terceira parte incluiu questões sobre os comportamentos e atitudes do quotidiano relacionados com reduzir, reutilizar e reciclar, para as quais se solicita uma das seguintes respostas: "Sempre", "Algumas vezes" e "Nunca", correspondendo a uma escala ordinal com pontuação 2,1 e 0 , respetivamente. A última parte destinou-se aos conhecimentos sobre a prática dos "3R's" em termos individuais e coletivas no IPG.

Realizou-se um pré-teste do instrumento que consistiu na sua aplicação a dez elementos da comunidade escolar do IPG. O instrumento foi respondido sem haver a necessidade de intervenção no decorrer do seu preenchimento, não se observando dificuldades quer na sua interpretação quer no seu preenchimento. A duração média de cada resposta ao questionário foi de cerca de 5 minutos.

$\mathrm{O}$ instrumento foi disponibilizado em formato digital por facilitar o seu preenchimento e o acesso ao mesmo, bem como minorar erros de preenchimento. Teve-se como objetivo abranger e obter a participação de toda a comunidade das escolas do IPG e, para tal, o instrumento foi distribuído via correio eletrónico institucional a toda a população alvo e esteve 
online entre novembro de 2016 e fevereiro de 2017. Neste processo de recolha de dados obtiveram-se 342 respostas válidas que constituem a amostra do estudo, correspondendo à técnica de amostragem não probabilística por conveniência, com uma margem de erro de 5,1 $\%$.

Para a realização da análise exploratória dos dados, foram utilizadas técnicas básicas de estatística descritiva. A dependência entre variáveis investigou-se através da aplicação do teste exato de Fisher (Pestana \& Gageiro, 2014), para variáveis qualitativas dicotómicas, e nos restantes casos aplicou-se o teste de independência do qui-quadrado de Pearson (Pestana \& Gageiro, 2014). Em determinadas situações recorreu-se ao cálculo de Intervalos de Confiança (IC) a 95\% e ao coeficiente alfa de Cronbach, por se considerarem pertinentes na análise em causa. Todas as conclusões apresentadas basearam-se num nível de significância de 5\%.

\section{RESULTADOS}

De seguida apresentam-se os resultados obtidos da análise dos dados caracterizando a amostra, os conhecimentos gerais sobre o tema "3R's" e os comportamentos e atitudes dos inquiridos sobre estas temáticas e sobre as políticas aplicadas no IPG.

\subsection{Caracterização da Amostra}

Os dados analisados neste estudo foram recolhidos no ano letivo 2016/2017 sendo, por isso, relevante referir a distribuição de estudantes, professores e funcionários por escola do IPG nesse período.

Assim, segundo a Direção Geral de Estatísticas da Educação e Ciência (DGEEC, 2018), o número total de estudantes inscritos no IPG era de 2640 , dos quais 1063 na ESTG (40,3\%), 765 na ESECD (29\%), 506 na ESS (19,1\%) e 306 na ESTH (11,6\%) (Tabela 1).

Em relação ao número de docentes e funcionários nas escolas do IPG, referente a dezembro de 2016 (Tabela 1), existiam 204 docentes: 46,6\% na ESTG, 24,5\% na ESECD, 19,1\% na ESS e 9,8\% na ESTH e 45 funcionários: $33,3 \%$ na ESTG, 24,4\% na ESECD, 22,2\% na ESS e 20\% na ESTH.

Tabela 1- Distribuição de professores, estudantes, e funcionários por escola do IPG em 2016/2017

\begin{tabular}{|c|c|c|c|c|c|c|c|c|c|}
\hline & & & & & & & & \multirow{3}{*}{\multicolumn{2}{|c|}{ Total }} \\
\hline & \multicolumn{6}{|c|}{ Vínculo com o IPG } & & \\
\hline & & \multicolumn{2}{|l|}{ Docentes } & \multirow{2}{*}{$\begin{array}{c}\text { Estudantes } \\
\mathbf{n}\end{array}$} & \multicolumn{3}{|c|}{ Funcionários } & & \\
\hline & Escola & $n$ & $\%$ & & $\mathrm{n}$ & $\%$ & $\%$ & $\mathrm{n}$ & $\%$ \\
\hline & ESTG & 95 & 46,6 & 1063 & 40,3 & 15 & 24,4 & 1173 & 40,6 \\
\hline & ESECD & 50 & 24,5 & 765 & 29 & 11 & 33,3 & 826 & 28,6 \\
\hline & ESS & 39 & 19,1 & 506 & 19,1 & 10 & 22,2 & 555 & 19,2 \\
\hline & ESTH & 20 & 9,8 & 306 & 11,6 & 9 & 20 & 335 & 11,6 \\
\hline \multirow{2}{*}{ Total } & $\mathrm{n}$ & 204 & 100 & 2640 & 100 & 45 & 100 & 2889 & 100 \\
\hline & $\%$ & 7,1 & $\ldots \ldots \ldots$ & 91,4 & $\ldots \ldots \ldots$ & 1,5 & $\ldots \ldots \ldots$ & 100 & ........ \\
\hline
\end{tabular}

$\mathrm{Na}$ amostra (Tabela 2) observou-se a seguinte representatividade das escolas do IPG: $42,4 \%$ da ESTG, $32,2 \%$ da ESS, $22,2 \%$ da ESTH e 3,2\% da ESECD. Em termos da distribuição dos docentes por escola constatou-se na amostra que 50\% eram da ESTG, 19,6\% da ESTH, 17,4\% 
da ESECD e $13 \%$ da ESS. Relativamente aos estudantes, a distribuição foi de $43 \%$ da ESTG, $35,2 \%$ da ESS, 21,5\% da ESTH e 0,4\% da ESECD. Quanto aos funcionários, 50\% eram da ESTH, $33,3 \%$ da ESS e $16,7 \%$ da ESECD, não havendo qualquer elemento da ESTG.

A distribuição dos 342 respondentes, tendo em conta o vínculo com o IPG, foi: $83 \%$ estudantes (10,8\% do total de inscritos), $13,5 \%$ docentes (22,6\% dos existentes em dezembro de 2016 ) $3,5 \%$ funcionários (26,7\% dos existentes em dezembro de 2016$)$.

Tabela 2- Distribuição de estudantes, professores e funcionários por escola do IPG na amostra

\begin{tabular}{|c|c|c|c|c|c|c|c|c|c|}
\hline & \multirow[b]{3}{*}{ Escola } & \multicolumn{6}{|c|}{ Vínculo com o IPG } & & \\
\hline & & \multicolumn{2}{|c|}{ Docente } & \multicolumn{2}{|c|}{ Estudante } & \multicolumn{2}{|c|}{ Funcionário } & \multicolumn{2}{|c|}{ Total } \\
\hline & & $\mathbf{n}$ & $\%$ & $n$ & $\%$ & $\mathrm{n}$ & $\%$ & $\mathrm{n}$ & $\%$ \\
\hline & ESECD & 8 & 17,4 & 1 & 0,4 & 2 & 16,7 & 11 & 3,2 \\
\hline & ESS & 6 & 13 & 100 & 35,2 & 4 & 33,3 & 110 & 32,2 \\
\hline & ESTG & 23 & 50 & 122 & 43 & 0 & 0 & 145 & 42,4 \\
\hline & ESTH & 9 & 19,6 & 61 & 21,5 & 6 & 50 & 76 & 22,2 \\
\hline \multirow{2}{*}{ Total } & $\mathrm{n}$ & 46 & 100 & 284 & 100 & 12 & 100 & 342 & 100 \\
\hline & $\%$ & 13,5 & .......... & 83 & $\ldots \ldots \ldots$ & 3,5 & $\ldots \ldots \ldots$ & 100 & $\ldots \ldots \ldots$ \\
\hline
\end{tabular}

Relativamente ao sexo dos respondentes observou-se um ligeiro predomínio do sexo feminino $(57,9 \%, n=198)$. Esse facto é idêntico entre os estudantes $(57,7 \%, n=164)$ e ligeiramente mais acentuado no caso dos docentes $(63 \%, \mathrm{n}=29)$, sendo o inverso no caso dos funcionários onde o sexo feminino estava representado por $41,7 \%(n=5)$. Relativamente ao tipo de curso frequentado pelos estudantes observou-se que $82,4 \%(n=234)$ eram alunos das licenciaturas, 9,5\% ( $n=27)$ dos CTeSP e 8,1\% ( $n=23)$ dos mestrados.

Considerando todos os participantes no estudo observou-se que a idade variava entre 17 e 68 anos com uma média de pouco mais que 27 anos (desvio-padrão de 11,24 anos), sendo que pelo menos $50 \%$ dos respondentes tinham 22 anos ou menos (Tabela 3). Analisando de forma parcial, segundo o vínculo com o IPG, constatou-se que a média de idades dos docentes era de pouco mais de 48 anos e com idades a variar entre 30 e 64 anos; a média de idades dos estudantes é de 23 anos e com idades a variar entre 17 e 53 anos; e a média de idades dos funcionários é de cerca de 43 anos e com idades a variar entre 25 e 60 anos.

Tabela 3- Estatísticas para a idade de estudantes, professores e funcionários na amostra

\begin{tabular}{llcccc} 
& & \multicolumn{3}{c}{ Vínculo com o IPG } & \\
\cline { 3 - 6 } & Estatística & Docente & Estudante & Funcionário & Total \\
\hline Média & & 48,4 & 23,1 & 43,3 & 27,2 \\
\hline \multirow{2}{*}{$\begin{array}{l}\text { 95\% Intervalo de Confiança } \\
\text { para Média }\end{array}$} & Limite inferior & 46,2 & 22,3 & 37,3 & 19,4 \\
\cline { 2 - 6 } & Limite superior & 50,5 & 23,8 & 49,2 & 35,2 \\
\hline Mediana & & 48,5 & 21,0 & 45,0 & 22,0 \\
\hline & Desvio Padrão & 7,2 & 6,3 & 9,3 & 11,2 \\
\hline & Mínimo & 30,0 & 17,0 & 25,0 & 17,0 \\
\hline & Máximo & 64,0 & 53,0 & 60,0 & 64,0 \\
\hline
\end{tabular}




\subsection{Conhecimentos gerais sobre o tema " $3 R^{\prime} S^{\prime \prime}$}

Sobre o tema em apreço "reduzir, reutilizar e reciclar", os inquiridos foram questionados acerca do seu grau de concordância ("Concordo", "Discordo", "Não sei”) relativamente a algumas afirmações (Figura 1).

De forma geral existe concordância com as afirmações apresentadas, todas acima de $50 \%$. Contudo, as percentagens de discordância mais elevadas surgiram nas afirmações "Tenho acesso fácil a ecopontos" (34,5\%, n=118) e "A utilização da tecnologia, apesar da poupança de papel, não tem diminuído o impacto ambiental" (31,9\%, $\mathrm{n}=109)$.

Além disso, é de salientar o desconhecimento manifestado pelos inquiridos relativamente às afirmações "A utilização da tecnologia, apesar da poupança de papel, não tem diminuído o impacto ambiental", $(15,2 \%, n=52)$, "A separação dos lixos cria um outro mundo de oportunidades de negócio", $(10,5 \%, n=36)$, e também "Estou bem informado sobre a política dos 3 Rs", $(7 \%, n=24)$.

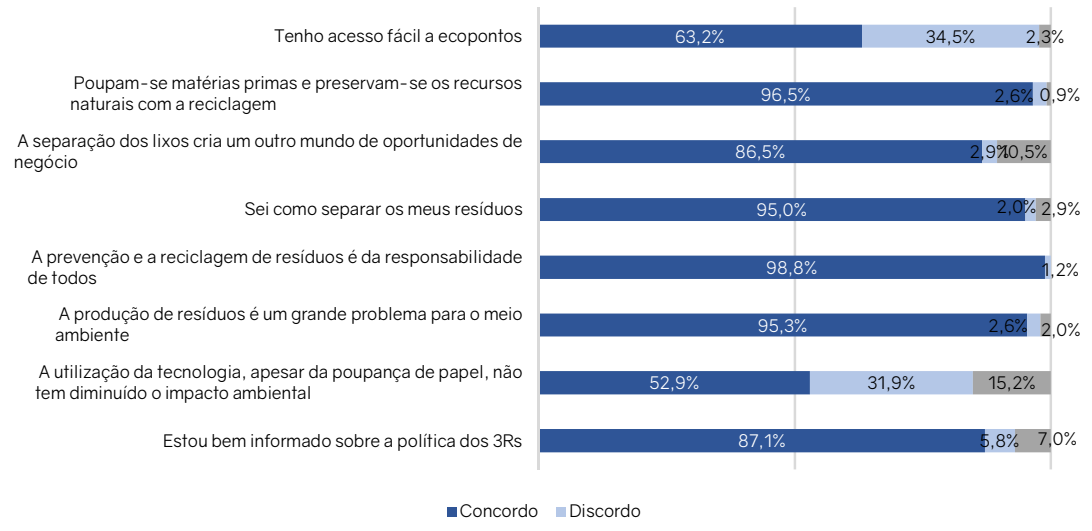

Figura 1- Grau de concordância com afirmações gerais sobre o tema reduzir, reutilizar e reciclar

Foi averiguada se a concordância dos participantes com as afirmações seria dependente do sexo, da escola do IPG a que estavam afetos, do tipo de vínculo (docente, estudante, funcionário) e, no caso dos estudantes, do tipo de curso (TeSP, Licenciatura e Mestrado) que frequentavam.

Os resultados indicaram que apenas na afirmação " $A$ utilização da tecnologia, apesar da poupança de papel, não tem diminuído o impacto ambiental" existia dependência face ao sexo dos indivíduos $(p=0,013)$, sendo o sexo feminino o que mais concorda com a afirmação. Para as restantes variáveis e nas afirmações onde foram verificadas as condições exigidas à obtenção de resultados válidos, com a aplicação do teste de independência do qui-quadrado de Pearson, concluiu-se que não existia dependência entre a concordância com as afirmações e a escola, vínculo ou tipo de curso. 


\subsection{Comportamentos}

Os inquiridos manifestaram-se em relação ao seu comportamento perante determinadas situações do quotidiano relacionados com reduzir, reutilizar e reciclar, tendo como opções a escala ordinal: "Sempre" (pontuação=2), "Algumas vezes" (pontuação=1) e "Nunca" (pontuação=0), nas 29 questões sobre o tema.

Considerando a pontuação da escala ordinal, referida anteriormente, em que na questão "Quando lava os dentes deixa a torneira aberta?" a pontuação foi invertida, determinou-se a mediana de todas as questões relativas aos comportamentos do quotidiano por participante. Desta forma, a mediana foi considerada uma medida de avaliação global dos comportamentos dos participantes no quotidiano.

Para se quantificar a consistência interna das 29 questões recorreu-se ao Alfa de Cronbach, que representa uma me da confiabilidade dos resultados, cujo valor foi de 0,85 correspondendo a uma boa consistência (Nunnally \& Bernstein, 1994).

Os resultados da avaliação global dos comportamentos no quotidiano foram: 0,6\% $(n=2)$ dos participantes com 0 ("Nunca"), 0,3\% ( $n=1)$ com valor entre 0 e 1,59,9\% ( $n=205)$ com 1 ("Algumas vezes"), 5,3\% com valor entre 1 e 2 e 33,9\% ( $n=116$ ) com 2 ("Sempre"). Observouse que $99,1 \%$ dos indivíduos apresentavam uma avaliação global do seu comportamento no quotidiano no que se refere a reduzir, reutilizar e reciclar que variava de "Algumas vezes" (=1) a "Sempre" (=2) optarem pela atitude adequada.

Além da avaliação global dos comportamentos no quotidiano, também as respostas dos participantes a cada uma das 29 questões foram analisadas (Figuras 2 e 3). Neste âmbito, e como se pode ver na Figura 2, destacam-se os comportamentos positivos, que estão associados a maiores percentagens na opção "Sempre", nas afirmações "Evita desperdiçar comida?" (86,3\%, $\mathrm{n}=295)$, "Utiliza a frente e o verso do papel para escrever?' $(80,7 \%, \mathrm{n}=276)$ "Imprime somente o necessário?', (76,3\%, $\mathrm{n}=261)$, "Reutiliza sacos de plástico/papel, envelopes, caixas?' (67,8\%, $\mathrm{n}=232)$ "Aquando da compra de eletrodomésticos privilegia a classe energética?', $(61,4 \%, \mathrm{n}=210)$ e, igualmente selecionadas, foram "Compra o suficiente para o consumo, evitando desperdício de produtos e alimentos?' e "Doa objetos e roupas que já não usa?' (59,4\%, n=203).

Acrescem, no mesmo sentido, mas com percentagens de resposta próximas dos $50 \%$ as afirmações: "Tem por hábito reciclar vidros?' (50\%, n=171), "Quando usa a máquina de lavar tem o cuidado de utilizar o aparelho em modo económico?' (49,7\%, n=170), "Quando utiliza carro opta por uma condução moderada para reduzir o consumo de combustivel?' (49,4\%, $\mathrm{n}=169)$ e "Tem por hábito reciclar pilhas?" $(48,8 \%, \mathrm{n}=167)$.

O comportamento negativo que mais se destacou foi relativamente à afirmação "Tem por hábito reciclar latas de alumínio/aço?', já que 20,5\% (n=70) dos participantes responderam "Nunca". 


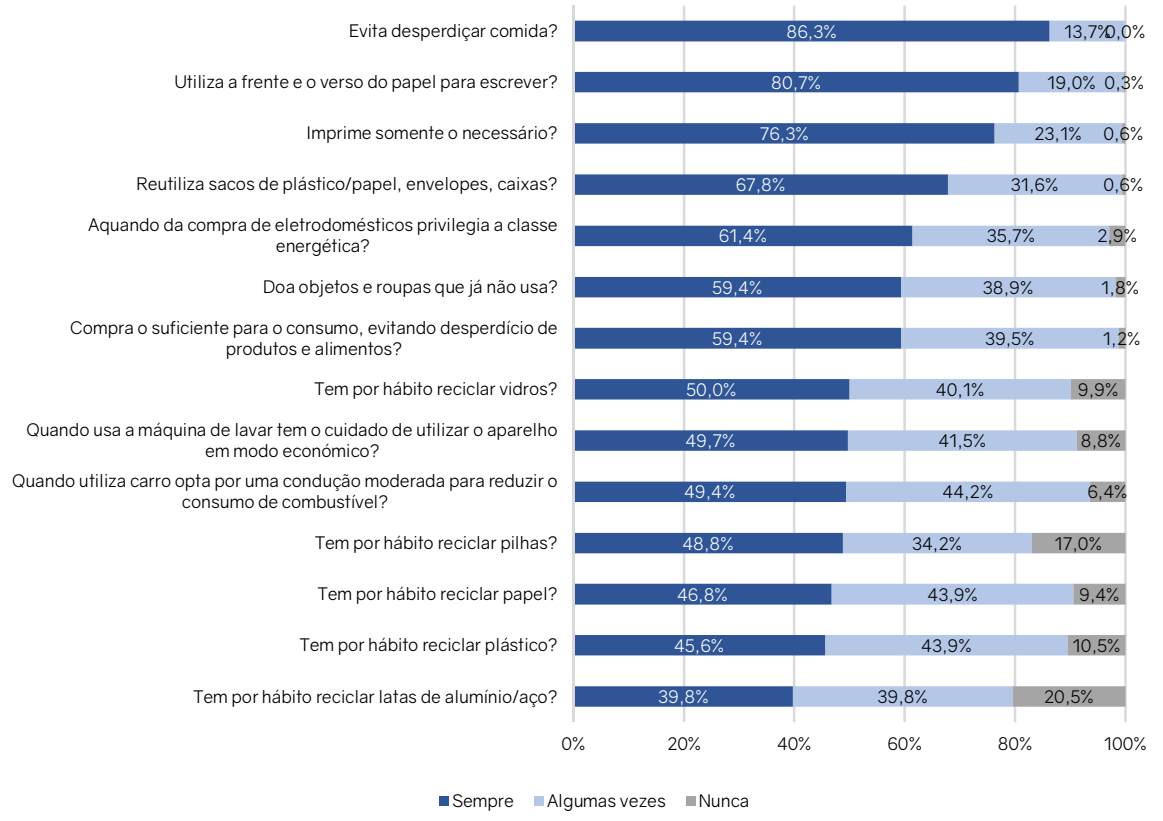

Figura 2 - Respostas dos inquiridos em relação a comportamentos do quotidiano relacionados com reduzir, reutilizar e reciclar

Como se pode ver na Figura 2, a afirmação "Quando lava os dentes deixa a torneira aberta?' realça-se no sentido positivo, porque 60,8\% ( $n=208)$ disse que "Nunca" o faz. Por outro lado, no sentido negativo, as afirmações "Nas suas deslocações dá preferência aos transportes públicos?' (33\%, n=113), "Compra artigos em segunda mão?' (31,6\%, n=108), "Reutiliza a água (de lavar vegetais etc.)" (29,5\%, $\mathrm{n}=101)$ e "Rejeita os sacos de plástico/papel quando os oferecem nas lojas para transportar as compras?' (26,6\%, $\mathrm{n}=91)$ ' 'Utiliza tinteiros reciclados?' $(26,3 \%, \mathrm{n}=90)$ e "Utiliza pilhas recarregáveis?" (21,9\%, $\mathrm{n}=75)$.

Dos resultados realça-se, ainda, a afirmação "Adquire produtos mais duráveis e menos descartáveis?', posto que $80,4 \%(n=275)$ dos participantes referiram que é uma opção que tomam "Algumas vezes". 


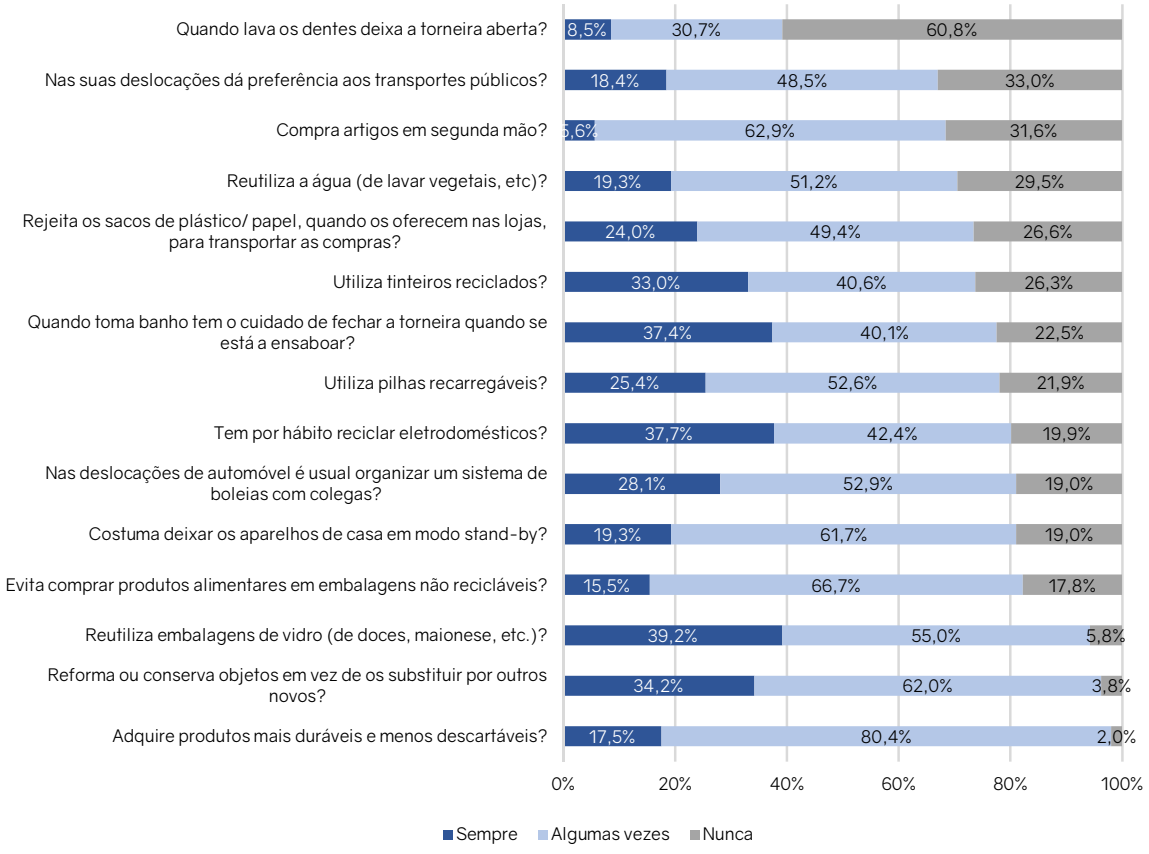

Figura 3 - Respostas dos inquiridos em relação a comportamentos do quotidiano relacionados com reduzir, reutilizar e reciclar

Foi investigada a dependência entre os comportamentos dos participantes, avaliadas pelas questões das Figuras 2 e 3, e o seu sexo, a escola do IPG a que estavam afetos, o tipo de vínculo (docente, estudante, funcionário) e, no caso dos estudantes, o tipo de curso (TeSP, Licenciatura e Mestrado) que frequentavam.

A análise revelou existir dependência entre o comportamento manifestado relativamente a "Quando usa a máquina de lavar tem o cuidado de utilizar o aparelho em modo económico?" e o sexo dos participantes $(p=0,005)$. Dos indivíduos que responderam "Nunca" $(n=30)$ destacaram-se os do sexo masculino $(n=21,70 \%)$ e de entre os que selecionaram "Sempre" $(n=170)$ destacou-se o sexo feminino $(n=103,60,6 \%)$.

Para as restantes variáveis e nas afirmações onde foram verificadas as condições exigidas à obtenção de resultados válidos, com a aplicação do teste de independência do qui-quadrado de Pearson, concluiu-se que não existia dependência entre os comportamentos/atitudes e a escola, vínculo ou tipo de curso.

\subsection{Conhecimentos sobre as práticas no IPG}

No que diz respeito ao conhecimento de que no IPG se procede à separação de resíduos, a maioria, 69\% ( $n=236)$, afirma sabê-lo. Contudo, a percentagem dos que dizem desconhecer esse facto $(n=106,31 \%)$ é considerável e deverá ser motivo de reflexão. 
Tabela 4- Perceção dos respondentes sobre a prática e política de separação de resíduos no IPG, por sexo, vínculo e unidade orgânica

\begin{tabular}{|c|c|c|c|c|c|c|c|c|c|c|c|}
\hline & & & \multicolumn{2}{|c|}{ Sexo } & \multicolumn{3}{|c|}{ Vínculo } & \multicolumn{4}{|c|}{ Unidade Orgânica (escola) } \\
\hline & & & Masculino & Feminino & Docente & Estudante & Funcionário & ESECD & ESS & ESTG & ESTH \\
\hline \multirow{5}{*}{ 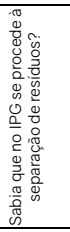 } & \multirow{2}{*}{ Não } & $n$ & 33 & 73 & 1 & 101 & 4 & 2 & 41 & 24 & 39 \\
\hline & & $\%$ & 22,9 & 36,9 & 2,2 & 35,6 & 33,3 & 18,2 & 37,3 & 16,6 & 51,3 \\
\hline & \multirow{2}{*}{ Sim } & $n$ & 111 & 125 & 45 & 183 & 8 & 9 & 69 & 121 & 37 \\
\hline & & $\%$ & 77,1 & 63,1 & 97,8 & 64,4 & 66,7 & 81,8 & 62,7 & 83,4 & 48,7 \\
\hline & \multicolumn{2}{|c|}{$\begin{array}{c}\text { Total } \\
(\%)\end{array}$} & $\begin{array}{c}144 \\
(42,1)\end{array}$ & $\begin{array}{c}198 \\
(57,9)\end{array}$ & $\begin{array}{c}46 \\
(13,5)\end{array}$ & $\begin{array}{l}284 \\
(83)\end{array}$ & $\begin{array}{c}12 \\
(3,5)\end{array}$ & $\begin{array}{c}11 \\
(3,2)\end{array}$ & $\begin{array}{c}110 \\
(32,2)\end{array}$ & $\begin{array}{c}145 \\
(42,4)\end{array}$ & $\begin{array}{c}76 \\
(22,2)\end{array}$ \\
\hline \multirow{5}{*}{ 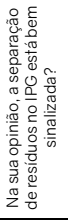 } & \multirow{2}{*}{ Não } & $n$ & 61 & 114 & 20 & 148 & 7 & 6 & 72 & 47 & 50 \\
\hline & & $\%$ & 42,4 & 57,6 & 43,5 & 52,1 & 2 & 54,5 & 65,5 & 32,4 & 65,8 \\
\hline & \multirow{2}{*}{ Sim } & $n$ & 83 & 84 & 26 & 136 & 5 & 5 & 38 & 98 & 26 \\
\hline & & $\%$ & 57,6 & 42,4 & 56,5 & 47,9 & 1,5 & 45,5 & 34,5 & 67,6 & 34,2 \\
\hline & \multicolumn{2}{|c|}{$\begin{array}{c}\text { Total } \\
(\%)\end{array}$} & $\begin{array}{c}144 \\
(42,1)\end{array}$ & $\begin{array}{c}198 \\
(57,9)\end{array}$ & $\begin{array}{c}46 \\
(13,5)\end{array}$ & $\begin{array}{l}284 \\
(83)\end{array}$ & $\begin{array}{c}12 \\
(3,5)\end{array}$ & $\begin{array}{c}11 \\
(3,2)\end{array}$ & $\begin{array}{c}110 \\
(32,2)\end{array}$ & $\begin{array}{c}145 \\
(42,4)\end{array}$ & $\begin{array}{c}76 \\
(22,2)\end{array}$ \\
\hline \multirow{5}{*}{ 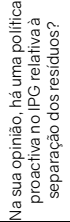 } & \multirow{2}{*}{ Não } & $n$ & 68 & 117 & 21 & 156 & 8 & 7 & 63 & 58 & 57 \\
\hline & & $\%$ & 47,2 & 59,1 & 45,7 & 54,9 & 66,7 & 63,6 & 57,3 & 40 & 75 \\
\hline & \multirow{2}{*}{ Sim } & $n$ & 76 & 81 & 25 & 128 & 4 & 4 & 47 & 87 & 19 \\
\hline & & $\%$ & 52,8 & 40,9 & 54,3 & 45,1 & 33,3 & 36,4 & 42,7 & 60 & 25 \\
\hline & \multicolumn{2}{|c|}{$\begin{array}{c}\text { Total } \\
(\%)\end{array}$} & $\begin{array}{c}144 \\
(42,1)\end{array}$ & $\begin{array}{c}198 \\
(57,9)\end{array}$ & $\begin{array}{c}464 \\
(13,5)\end{array}$ & $\begin{array}{l}284 \\
(83)\end{array}$ & $\begin{array}{c}12 \\
(3,5)\end{array}$ & $\begin{array}{c}11 \\
(3,2)\end{array}$ & $\begin{array}{c}110 \\
(32,2)\end{array}$ & $\begin{array}{c}145 \\
(42,4)\end{array}$ & $\begin{array}{c}76 \\
(22,2)\end{array}$ \\
\hline
\end{tabular}

Com base nos dados da Tabela 4 constatou-se que são os homens que em maior proporção reconhecem a realização da separação de resíduos, comparativamente, às mulheres e, em maior proporção, os docentes, comparativamente, aos estudantes e funcionários. Contudo, observaram-se perceções diferentes sobre a questão em causa entre escolas, sendo mais reconhecido na ESTG e na ESECD e menos na ESS e na ESTH. Em complemento a esta informação, existe evidência estatística de que o sexo $(p=0,004)$ e o tipo de vínculo dos inquiridos com o IPG $(p<0,001)$ estão associados ao reconhecimento da prática de reciclagem na instituição, destacando-se os homens e os docentes. A mesma conclusão se obteve relativamente à escola dos inquiridos $(p<0,001)$ destacando-se a ESTG. Refira-se que os dados da ESECD não permitiram a realização de tal avaliação.

No que diz respeito à questão sobre se a separação de resíduos no IPG está bem sinalizada (Tabela 4) existe uma similitude percentual entre os que consideraram que sim ( $n=167,48,8 \%$ ) e que não $(n=175,51,2 \%)$, apesar da maioria se ter manifestado pelo não. Todavia, a opinião acerca da referida sinalização depende do sexo $(p=0,004)$ dos respondentes, com evidência estatística de que os homens consideraram haver boa sinalização ao contrário das mulheres.

De forma análoga, existe uma relação de dependência com a escola do IPG $(p<0,001)$ a que os indivíduos estão afetos, destacando-se a ESTG por a maioria dos respondentes ter considerado que há uma boa sinalização ao contrário das restantes escolas ESTH e ESS, tendo-se excluído a ESECD pela falta de dados. Pelo contrário, não há relação entre a opinião dos indivíduos acerca da sinalização e o seu vínculo ao IPG $(p=0,488)$, embora os docentes tenham sido os únicos em que a maioria indicou considerar haver boa sinalização.

No que diz respeito à existência de uma política proactiva no IPG relativa à separação de resíduos (Tabela 4) houve uma maioria que considerou que não ( $n=185,54,1 \%)$. 
Por outro lado, observou-se uma dependência estatisticamente significativa entre a perceção acerca da política proactiva na separação de resíduos e o sexo dos indivíduos $(p=0,037)$, sendo os homens que, maioritariamente, consideraram que tal política existe no IPG, estando as mulheres em sentido contrário. Os resultados também indicaram que a mesma dependência existe com a escola do IPG $(p<0,001)$, excluindo-se a ESECD pela falta de dados. Destacouse a ESTG, face à ESS e à ESTH, com mais respostas a corroborarem a existência de tal política. $O$ vínculo dos indivíduos com o IPG não apresentou qualquer relação estatisticamente significativa $(p=0,339)$, com a sua opinião manifestada pelos inquiridos.

No que diz respeito ao fazer a separação correta do lixo no IPG (Tabela 5) 12,9\% ( $n=44)$, afirmaram "Nunca" o fazer. Contudo, a percentagem que dizem apenas fazê-lo às vezes é considerável, $44,4 \%(n=152)$, e maior do que a daqueles que indicaram fazê-lo "Sempre" $(n=146,42,7 \%)$. A análise realizada permitiu concluir que o hábito de separar o lixo está relacionado com o sexo $(p=0,003)$, com o vínculo ao IPG $(p<0,001)$ e com a escola $(p<0,001)$, tendo sido excluída a ESECD.

Além disso, o reconhecimento da realização correta de separação de lixo é maior nos docentes e funcionários do que entre estudantes, é também maior nos homens face às mulheres e, ainda, mais reconhecido pelos elementos da ESTG face aos da ESS e da ESTH (Tabela 5).

Tabela 5- Hábitos dos respondentes na separação correta do lixo nas instalações do IPG, por sexo, vínculo e unidade orgânica

Costuma separar corretamente o lixo nas instalações do IPG?

\begin{tabular}{ccccccccc}
\cline { 3 - 7 } & & \multicolumn{2}{c}{ Algumas vezes } & \multicolumn{2}{c}{ Nunca } & \multicolumn{2}{c}{ Sempre } & \\
\cline { 3 - 7 } & & $\mathrm{N}$ & $\%$ & $\mathrm{n}$ & $\%$ & $\mathrm{n}$ & $\%$ & Total $(\%)$ \\
\hline \multirow{2}{*}{ Sexo } & Masculino & 56 & 38,9 & 12 & 8,3 & 76 & 52,8 & $144(42,1)$ \\
& Feminino & 96 & 48,5 & 32 & 16,2 & 70 & 35,4 & $198(57,9)$ \\
\hline \multirow{2}{*}{ Vínculo } & Docente & 13 & 28,3 & 1 & 2,2 & 32 & 69,6 & $46(13,5)$ \\
& Estudante & 134 & 47,2 & 43 & 15,1 & 107 & 37,7 & $284(83)$ \\
& Funcionário & 5 & 41,7 & 0 & 0 & 7 & 58,3 & $12(3,5)$ \\
\hline \multirow{2}{*}{ Unidade } & ESECD & 3 & 27,3 & 0 & 0 & 8 & 72,7 & $11(3,2)$ \\
Orgânica & ESS & 53 & 48,2 & 15 & 13,6 & 52 & 38,2 & $110(32,2)$ \\
(escola) & ESTG & 60 & 41,4 & 7 & 4,8 & 78 & 53,8 & $145(42,4)$ \\
& ESTH & 36 & 47,4 & 22 & 28,9 & 18 & 23,7 & $76(22,2)$ \\
\hline
\end{tabular}

\section{DISCUSSÃO DOS RESULTADOS}

Os resultados obtidos indicam que os participantes detêm um bom conhecimento sobre o tema "3R's", tendo em conta a concordância manifestada com as afirmações apresentadas sobre o tema. Esta conclusão é corroborada pelo estudo realizado por Embong et al. (2013), em estudantes do ensino secundário na Malásia, apesar de tal avaliação ser baseada noutra metodologia. No mesmo sentido, Târtiu (2011), Erhabor e Don (2016) e Alibeli e Johnson (2009), que realizaram estudos sobre o tema em estudantes do ensino superior, observaram resultados similares. Por outro lado, Querino, Pereira e Barros (2018) concluíram que os participantes no seu estudo revelaram atitudes negativas face a reduzir, reutilizar e reciclar que poderiam estar associadas à falta de conhecimentos sobre o tema já que manifestaram uma perceção confusa sobre o mesmo. 
Os resultados da avaliação global dos comportamentos no quotidiano face a reduzir, reutilizar e reciclar, bem como das respostas a cada uma das questões indicam que grande parte dos participantes tem preocupações ambientais, porque revelaram hábitos e práticas em prol do ambiente. No mesmo sentido apontam os estudos de Târtiu (2011), Embong et al. (2013). Contudo, alguns estudos (Latif \& Hoque, 2018; Querino, Pereira, \& Barros, 2018) referem ter observado uma reduzida prática de comportamentos de reduzir, reutilizar e reciclar.

O que se segue remete-se às práticas de separação de resíduos no IPG. Na revisão bibliográfica realizada, não se encontrou uma avaliação similar que permitisse proceder à comparação de resultados.

No reconhecimento da prática de reciclagem no IPG, os resultados indicaram que se destacam os homens, os docentes e a ESTG. Contudo, observou-se que não é desprezível o número de participantes que disse desconhecer que no IPG se procede à separação de resíduos. Tal merece ser motivo de reflexão no sentido de se implementarem medidas conducentes ao aumento do conhecimento nesta comunidade.

Em termos da sinalização dos ecopontos no IPG, os dados permitiram concluir que os homens e os participantes afetos à ESTG se destacaram positivamente. Contudo, a maioria dos participantes considera que não existe uma boa sinalização, devendo este ponto ser alvo de atenção, no sentido de se estudarem e implementarem medidas conducentes a uma melhor sinalização.

No que diz respeito à existência de uma política proativa no IPG destacaram-se os homens e a ESTG, pela positiva, mas a maioria dos participantes manifestou-se negativamente. Assim, este resultado exige uma profunda reflexão de forma que o IPG melhore a sua política em termos de separação dos resíduos e que delineie estratégias de comunicação da mesma, nomeadamente na comunidade académica.

Por fim, destaca-se o facto de 12,9\% dos participantes terem referido que "Nunca" fazem a correta separação resíduos no IPG.

Uma limitação do estudo foi o reduzido número de participantes numa das escolas e também num dos vínculos ao IPG.

\section{CONCLUSÃO}

O desafio da 8a edição da EWWR bem como a atualidade e premência do tema associado ao facto de o estudo se ter realizado no contexto de uma instituição de ensino superior, que tem responsabilidades acrescidas para com a sociedade, nomeadamente na sua educação e formação, justificam a pertinência do presente trabalho.

Dos resultados apresentados destaca-se o facto de ser considerável a percentagem de participantes que referiram que não têm acesso fácil a ecopontos e que consideraram que a utilização da tecnologia não tem diminuído o impacto ambiental dos resíduos. Tal poderá apontar para a necessidade de as entidades públicas avaliarem a cobertura de ecopontos. Por outro lado, talvez seja pertinente identificar de que forma se poderá utilizar a tecnologia para diminuir impactos ambientais. Refira-se, por exemplo, que existem organizações em que os documentos estão em duplicado, formatos digital e papel.

No sentido positivo destacaram-se as práticas individuais de evitar desperdiçar comida e de imprimir apenas o necessário utilizando frente e verso do papel, bem como, os cuidados em não desperdiçar água ao lavar os dentes, o ter cuidado na classe energética dos 
eletrodomésticos, o reutilizar sacos de plástico/papel, envelopes, caixas e doar objetos e roupas que já não se usa.

Relativamente às práticas e conhecimentos no IPG, concluiu-se que nem todos os respondentes sabem que no IPG se procede à separação de resíduos, que a sinalização não é visível para grande parte dos respondentes e que a maioria considera não haver uma política proactiva de separação de resíduos. Desta forma, seria desejável que no IPG se implementassem medidas que tornassem visíveis os ecopontos e que promovessem as práticas de Reduzir, Reutilizar e Reciclar envolvendo estudantes, funcionários e docentes.

Retomando o principal objetivo do estudo, o de aferir os conhecimentos e práticas da comunidade escolar do IPG relativamente à Redução, Reutilização e Reciclagem dos resíduos pode concluir-se, em termos gerais, que se observaram resultados positivos relativamente aos conhecimentos e comportamentos dos indivíduos. Contudo, quando se centrou a análise nos conhecimentos/práticas no IPG observou-se que existem lacunas que exigem intervenção.

Nesse sentido, constata-se que, na área da educação e formação o IPG tem aumentado nos últimos anos as visitas de estudo, nomeadamente ao CIRVER (Centros Integrados de Recuperação, Valorização e Eliminação de Resíduos), à Resiestrela (centro de tratamento de resíduos sólidos urbanos), à ETAR localizada em São Miguel na Guarda, à Serra da Estrela, entre outras. No sentido de promover o debate e divulgar o conhecimento científico na área, foram realizadas palestras e cursos nas temáticas da Hidráulica, Recursos Hídricos e Ambiente em parceria/protocolo com a Ordem dos Engenheiros Técnicos. Relativamente a projetos desenvolvidos em contexto académico refiram-se, por exemplo, os seguintes: "um sistema de reutilização e reciclagem de águas cinzentas em edifícios" e "um sistema inteligente de gestão de resíduos sólidos urbanos para reciclagem".

Em termos de investigação, O IPG tem um projeto da monitorização da qualidade do ar da Guarda por meio da realização de ensaios físico-químicos e biológicos com recurso a uma unidade móvel. Por outro lado, para apoiar a investigação, a instituição tem vindo a reforçar em quantidade e qualidade os seus laboratórios, nomeadamente na área ambiental, como por exemplo os Laboratórios de Climatização e Ambiente (LCA), de Monitorização e Investigação Ambiental (LaBMIA), Centro de Eletrotecnia e Energia (CEE) e Centro de Potencial e Inovação de Recursos Naturais (CPIRN). Esses, para além de apoiarem o ensino, prestam serviços ao exterior, nomeadamente à indústria.

Apesar das ações que têm sido realizadas e da investigação no IPG, os resultados deste trabalho sugerem, como recomendação, que existe trabalho institucional a fazer no sentido de promover a mudança de comportamentos e atitudes na comunidade académica. Desde logo, para se alcançar um desenvolvimento sustentável é importante saber promover uma ética para a sustentabilidade, nomeadamente na oferta de formação não-formal e formal nesta área, quer para a comunidade académica quer para a comunidade local. Simultaneamente, é importante que o IPG promova parcerias e redes colaborativas no sentido de abarcar a transdisciplinaridade nos âmbitos ambiental, cultural, social e económico.

\section{REFERÊNCIAS}

Agência Portuguesa do Ambiente (APA). Portal da Agência Portuguesa do Ambiente (Portugal). Disponível em: < https://apambiente.pt/>. Acesso em: 06 out. 2018.

Alibeli, M. A., \& Johnson, C (2009). Environmental Concern: A Cross National Analysis. Journal of International and Cross-Cultural Studies, 3 (1), 1-10. 
Chan, R. Y. K (1999). Environmental Attitudes and Behavior of Consumers in China: Survey Findings and Implications. Journal of International Consumer Marketing, 11, 11 (4), 25-52.

Chierrito-Arruda, E., Rosa, A. L. M., Paccola, E. A.S, Macuch, R. S., \& Grossi-Milani, R. (2018). Comportamento Pró-Ambiental e Reciclagem: Revisão de Literatura e Apontamentos Para as Políticas Públicas. Ambiente \& Sociedade, São Paulo, 21, 1-18.

Decreto-Lei n.o 73/2011 de 17 de junho. Diário da República, n.o 116, Série I. Lisboa: Ministério do Ambiente e do Ordenamento do Território.

Demoly, K. R. A., \& Santos J. S. B (2018). Aprendizagem, Educação Ambiental e Escola: modos de en-agir na experiência de estudantes e professores. Ambiente \& Sociedade, São Paulo, 21,1-20.

Direção Geral de Estatísticas e Educação e Eiência (Portugal). Disponível em: <http://www.dgeec.mec.pt/np4/18/> Acesso em: 06 out. 2018.

Embong, A. M., Hashim, H. M., Noor, A. M., \& Malik, N. A. (2013). Assessing the Understanding and Practices of "3R's" among the Secondary School Students. 13th International Conference on Environment and Electrica/Engineering, Wroclaw, Poland, 1-3.

Erhabor, N. I., \& Don, J. U (2016). Impact of Environmental Education on the Knowledge. International Journal of Environmental \& Science Education, 11 (2), 5367-5375.

ERSAR. Entidade Reguladora dos Serviços de Águas e Resíduos (Portugal). Disponível em: <http://www.ersar.pt> Acesso em: 06 out. 2018.

EWWR. European Week for Waste Reduction (Europa). Disponível em: <http://www.ewwr.eu/en > Acesso em: 06 out. 2018.

Latif, M. A., \& Hoque, A. F. (2018). Domestic Waste Management of Dhaka City for Reuse and Recycle. European Journal of Business and Social Sciences, 1, 27 - 42.

Naturlink. Informação Ambiental (Portugal). Disponível em: <http://naturlink.pt/> Acesso em: 06 out. 2018.

Nunnally, J., \& Bernstein, I. (1994). Psychometric theory. McGraw-Hill.

Pandey, R. U., Surjan, A., \& Kapshe, M. (2018). Exploring linkages between sustainable consumption and prevailing green practices in reuse and recycling of household waste: Case of Bhopal city in India. Journal of Cleaner Production, 173, 49-59.

Pestana, M. H. \& Gageiro, J. N. (2014). Análise de Dados para Ciências Sociais - A Complementaridade do SPSS (6a Edição), Edições Sílabo, Lisboa.

Portaria no 187-A/2014, de 17 de setembro. Diário da República n.o 179, Série I. Lisboa: Presidência do Conselho de Ministros.

Querino, L. A. L., Pereira, J. P. G., \& Barros, M. K. L. V. (2018). Análise da percepção dos moradores de São Sebastião de Lagoa de Roça (pb) quanto a redução, reutilização e reciclagem de resíduos sólidos. Revista Brasileira de Educação Ambiental, 13 (2), 228-245.

Tadess, T., Ruijs, A, \& Hagos, F. (2008). Household waste disposal in Mekelle City, Northern Ethiopia. Waste Management, 28, 2003-2012.

Târtiu, V. (2011). Evaluation of Attitudes \& Knowledge Regarding Municipal Waste among Students. Case study: Bucharest Academy of Economic Studies. Economia Seria Management, 14 (1), 263-276.

VALORSUL (Portugal). Disponível em: <http://www.valorsul.pt> Acesso em: 06 out. 2018.

Wehrmeyer, W., \& Mcneil, M. (2000). Activists, Pragmatists, Technophiles and Tree-huggers? Gender Differences in Employees' Environmental Attitudes. Journal of Business Ethics, 28 (3), 211 222. 


\section{Conhecimento e práticas sobre Reduzir, Reutilizar e Reciclar}

No âmbito da Semana Europeia da Prevenção de Resíduos, pretende-se perceber qual é o

conhecimento e quais são as práticas da comunidade académica do IPG no que diz respeito aos

resíduos. Todas as informações recolhidas são anónimas e apenas serão utilizadas para os fins do estudo.

$\mathrm{O}$ questionário está dividido em quatro partes.

*Obrigatório

\section{Parte I}

1. Sexo *

Marcar apenas uma oval.

Feminino

Masculino

2. Indique a sua idade (anos): *

3. A que escola pertence? *

Marcar apenas uma oval.

Escola Superior de Educação, Comunicação e Desporto

Escola Superior de Tecnologia e Gestão

Escola Superior de Saúde

Escola Superior de Turismo e Hotelaria

4. Indique o seu vínculo com o IPG: *

Marcar apenas uma oval.

Estudante

Docente Passe para a pergunta 9.

Funcionário Passe para a pergunta 9

\section{Qual é o curso que frequenta?}

5. *

Marcar apenas uma oval.

Curso Técnico Superior Profissional Passe para a pergunta 6.

Licenciatura Passe para a pergunta 7.

Mestrado Passe para a pergunta 8.

\section{Curso Técnico Superior Profissional}


6. Escolha o curso que frequenta: * Marcar apenas uma oval.

Acompanhamento de Crianças e Jovens Passe para a pergunta 9.
Comunicação, Protocolo e Organização de Eventos Passe para a pergunta 9.
Cozinha e Produção Alimentar Passe para a pergunta 9.
Desportos de Montanha Passe para a pergunta 9.
Desenvolvimento de Aplicações Informáticas Passe para a pergunta 9.
Energias Renováveis e Eficiência Energética Passe para a pergunta 9.
Gerontologia Passe para a pergunta 9.
Gestão e Comércio Internacional Passe para a pergunta 9.
Infraestruturas de Cloud, Redes e Data Center
Manutenção Industrial Eletromecatrónica
Repórter de Som e Imagem passe para a pergunta 9.
Testes de Software Passe para a pergunta 9.
para a pergunta 9.

\section{Licenciatura}

7. Escolha o curso que frequenta: * Marcar apenas uma oval.

(D) Animação Sociocultural Passe para a pergunta 9.

Comunicação Multimédia Passe para a pergunta 9.

Comunicação e Relações Públicas Passe para a pergunta 9 .

Contabilidade Passe para a pergunta 9.

Design de Equipamento Passe para a pergunta 9.

Desporto Passe para a pergunta 9.

Educação Básica Passe para a pergunta 9.

Engenharia Civil Passe para a pergunta 9.

Engenharia Informática Passe para a pergunta 9.

Enfermagem Passe para a pergunta 9.

Engenharia Topográfica Passe para a pergunta 9.

Energia e Ambiente Passe para a pergunta 9.

Farmácia Passe para a pergunta 9.

Gestão Passe para a pergunta 9

Gestão Hoteleira Passe para a pergunta 9.

Gestão de Recursos Humanos Passe para a pergunta 9

Marketing Passe para a pergunta 9.

Restauração e Catering Passe para a pergunta 9.

Turismo e Lazer Passe para a pergunta 9.

Passe para a pergunta 9

\section{Mestrado}


8. Escolha o curso que frequenta: *

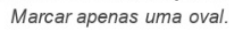

\section{Parte II}

Indique o seu grau de concordância com as seguintes afirmações:

9. *

Marcar apenas uma oval por linha.

Estou bem informado sobre a
politica dos 3Rs.
A utilização da tecnologia, apesar
da poupança de papel, não tem
diminuído o impacto ambiental.
A produção de resíduos é um
grande problema para o meio
ambiente.
A prevenção e a reciclagem de
residuos é da responsabilidade de
todos.
Sei como separar os meus
residuos.
A separação dos lixos cria um
outro mundo de oportunidades de
negócio.
Poupam-se matérias primas e
preservam-se os recursos
naturais com a reciclagem.
Tenho acesso fácil a ecopontos.

\section{Parte III}

Responda às seguintes perguntas: 
10. *

Marcar apenas uma oval por linha.

Sempre Algumas vezes Nunca

Adquire produtos mais duráveis e
menos descartáveis?
Compra artigos em segunda mão?
Compra o suficiente para o
consumo, evitando desperdício de
produtos e alimentos?
Evita comprar produtos
alimentares em embalagens não
recicláveis?
Nas suas deslocações dá
preferência aos transportes
públicos?
Nas deslocações de automóvel é
usual organizar um sistema de
boleias com colegas?
Rejeita os sacos de plástico/
papel, quando os oferecem nas
lojas, para transportar as
compras?
Evita desperdiçar comida?
Imprime somente o necessário?
Quando lava os dentes deixa a
tomeira aberta?

\section{Parte III}

Responda às seguintes perguntas:

11. *

Marcar apenas uma oval por linha.

Quando toma banho tem o
cuidado de fechar a torneira
quando se está a ensaboar?
Costuma deixar os aparelhos de
casa em modo stand-by?
Aquando da compra de
eletrodomésticos privilegia a
classe energética?
Quando usa a máquina de lavar
tem o cuidado de utilizar o
aparelho em modo económico?
Quando utiliza carro opta por uma
condução moderada para reduzir o
consumo de combustivel?
Utiliza a frente e o verso do papel
para escrever?
Reforma ou conserva objetos em
vez de os substituir por outros
novos?
Reutiliza embalagens de vidro (de
doces, maionese, etc.)?
Utiliza tinteiros reciclados?
Utiliza pilhas recarregáveis?

Parte III

Responda às seguintes perguntas: 
12. *

Marcar apenas uma oval por linha.

\section{Sempre Algumas vezes Nunca}

Reutiliza sacos de plástico/papel,
envelopes, caixas?
Doa objetos e roupas que já não
usa?
Reutiliza a água (de lavar
vegetais, etc)?
Tem por hábito reciclar papel?
Tem por hábito reciclar vidros?
Tem por hábito reciclar plástico?
Tem por hábito reciclar pilhas?
Tem por hábito reciclar
eletrodomésticos?
Tem por hábito reciclar latas de
aluminio /aço?

\section{Parte IV}

Responda às seguintes questões sobre práticas no IPG.

13. Sabia que no IPG se procede à separação de resíduos? * Marcar apenas uma oval.

$\bigcirc \operatorname{sim}$

$\bigcirc$ Não

14. Na sua opinião, a separação de resíduos no IPG está bem sinalizada? * Marcar apenas uma oval.

$\operatorname{Sim}$

Não

15. Na sua opinião, há uma política proactiva no IPG relativa à separação dos resíduos? * Marcar apenas uma oval.

Sim

Não

16. Costuma separar corretamente o lixo nas instalações do IPG? * Marcar apenas uma oval.
Sempre
Algumas vezes
Nunca

17. Tem alguma sugestão quanto a este tema que queira partilhar? 
130222017 Conhecimento e práticas sobre Reduzir, Reutilizar e Reciclar

Muito obrigada pela sua colaboração!

Com tecnologia

Hoogle Forms 
